\title{
Mortality Trends for Neglected Tropical Diseases in the State of Sergipe, Brazil, 1980-2013
}

\author{
Marcos Antônio Costa de Albuquerque ${ }^{1,2^{*}}$, Danielle Menezes Dias ${ }^{1 \dagger}$, Lucas Teixeira Vieira $^{1 \dagger}$, \\ Carlos Anselmo Lima ${ }^{1,2+}$ and Angela Maria da Silva ${ }^{1,2+}$
}

\begin{abstract}
Background: Neglected Tropical Diseases are a set of communicable diseases that affect the population so low socioeconomic status, particularly 1.4 billion people who are living below the poverty level. This study has investigated the magnitude and mortality time trends for these diseases in the state of Sergipe, Northeast Region of Brazil.

Methods: We conducted an ecological study of time series, based on secondary data derived from the Mortality Information System of the Ministry of Health. The mortality rates (crude, age-standardized rates and proportional ratio) were calculated from the deaths due to Neglected Tropical Diseases in the state of Sergipe, from 1980 to 2013. The time trends were obtained using the Joinpoint regression model.

Results: Three hundred six thousand and eight hundred seventy-two deaths were certified in the state and Neglected Tropical Diseases were mentioned as the underlying cause in 1,203 certificates (0.39\%). Mean number of deaths was 35.38 per year, and crude and age-standardized mortality rates were, respectively: 2.16 per 100000 inhabitants (95\% Cl: 1.45-2.87) and 2.87 per 100000 inhabitants (95\% Cl: 1.93-3.82); the proportional mortality ratio was $0.41 \%$ (95\% Cl: $0.27-0.54)$. In that period, Schistosomiasis caused 654 deaths (54.36\%), followed by Chagas disease, with 211 (17.54\%), and by Leishmaniases, with $142(11.80 \%)$ deaths. The other diseases totalized 196 deaths (16.30\%). There were increasing mortality trends for Neglected Tropical Diseases, Schistosomiasis and Chagas disease in the last 15 years, according to the age-standardized rates, and stability of the mortality trends for Leishmaniases.

Conclusions: The Neglected Tropical Diseases show increasing trends and are a real public health problem in the state of Sergipe, since they are responsible for significant mortality rates. The following diseases call attention for showing greater number of deaths in the period of study: Schistosomiasis, Chagas disease and Leishmaniases. We finally suggest that public managers take appropriate actions to develop new strategies in epidemiological and therapeutic surveillance, and in the follow-up of these patients.
\end{abstract}

Keywords: Mortality, Neglected tropical diseases, Trends, Joinpoint

\footnotetext{
* Correspondence: albuquerquemac@uol.com.br

${ }^{\dagger}$ Equal contributors

${ }^{1}$ University Hospital, Federal University of Sergipe, Rua Claudio Batista s/n, B. Santo Antonio, Aracaju, SE 49060-108, Brazil

${ }^{2}$ Post-doc Medicine Unit, Federal University of Sergipe, Rua Claudio Batista s/n, B. Santo Antonio, Aracaju, SE 49060-108, Brazil
} 


\section{Multilingual abstracts}

Please see Additional file 1 for translations of the abstract into the five official working languages of the United Nations.

\section{Background}

Neglected Tropical Diseases (NTDs) are a set of communicable diseases that affect the population so low socioeconomic status, particularly 1.4 billion people who are living below the poverty level, mainly those located in the Sub-Saharan Africa, Caribbean, Asia, and Latin America [1]. They represent a group of diseases of high global prevalence, namely: Leishmaniases, Schistosomiasis, Onchocerciasis, Lymphatic filariasis, Taeniasis, Cysticercosis, Dracunculiasis, Chagas disease, Human African trypanosomiasis, Leprosy, Dengue, Buruli ulcer, Echinococcosis, endemic treponematoses (Yaws, Pinta, Bejel), Rabies, Trachoma, foodborne trematodiases and some soil-transmitted helminthiases (Ascaris lumbricoides, Trichuris trichiura and Hookworm infection) [2]. These diseases are so called because the research investments are generally not reverted to development and amplification of access to new drugs, diagnostic tests, vaccines and other technologies for their prevention and control [3].

Globally, Hookworm infection is the most prevalent neglected tropical disease (NTD), and the number of deaths due to Leishmaniasis, Schistosomiasis and human African trypanosomiasis (HAT) is extremely high [4]. The highest incidence rate of these diseases in Latin America and the Caribbean occurs in Brazil, where approximately 40 million people live in extreme poverty. Most of Brazil's poorest people are infected with one or more NTDs, especially either hookworms or roundworms, or both [5]. NTDs are more prevalent in the Northeast and North Region of the country, where we find the lowest Human Development Indices (HDIs). Most NTDs occur in several Brazilian regions; some occur in outbreaks, such as Onchocerciasis, which is limited to the Yanomami indigenous zone (North Region), and lymphatic Filariasis, strongly concentrated in the metropolitan area of Recife [4].

Due to lack of data on mortality impact caused by NTDs in the State of Sergipe, Northeast Region of Brazil, the present paper provides information concerning these neglected diseases, which may contribute to warn managers about the need to prioritize and readjust actions related to surveillance, support, therapeutic quality, and control of these diseases. Here, we analysed the magnitude and mortality time trends for the Neglected Tropical Diseases in the state of Sergipe, Brazil, emphasizing the underlying causes of deaths within the period of study.

\section{Methods}

Study area

Sergipe is the smaller state of Brazil, total area is 21 $918.493 \mathrm{~km}^{2}$, and accounts for $0.26 \%$ of the national total area. It is located in the Northeast, comprising 75 towns, according to the Instituto Brasileiro de Geografia e Estatística (IBGE) [6]. The IBGE estimated a population of 2219574 inhabitants for Sergipe in 2014, population density is 94.36 inhabitants $/ \mathrm{km}^{2}$, and life expectancy at birth is 72.1 years [7]. The general climate in the state is semiarid, consisting of seven to 11 dry months. The average annual pluviometric index fluctuates, and irregular and poorly distributed rains occur throughout the year. Waste water treatment is mostly made through septic tanks and part of the effluents generated in the community is released in the general waste water network and, in some cities, directly to the rain water system, without the duly treatment. Approximately 50\% of the population lives within the Poverty Index [8]. At least the following NTDs are recognized endemically in Sergipe: Leishmaniases, Schistosomiasis, Chagas disease, Dengue, Leprosy, Taeniasis, soil-transmitted helminthiases (Ascaris lumbricoides, Trichuris trichiura and Hookworm infection).

\section{Study design, population and data sources}

We designed an ecological study of time series to assess mortality trends for Neglected Tropical Diseases in the state of Sergipe, from 1980 to 2013. Mortality data, which are of public domain, were obtained directly from the Mortality Information System (SIM) for the state of Sergipe, Brazil, and defined by the underlying cause of deaths. The NTDs used, corresponding ICD-9 (1980-1995) and ICD10 (1996-2013), were obtained from the WHO list [2] and are summarized in Table 1 . In addition to joint analysis, the three main ones were analyzed individually. The information regarding population was derived from the demographic census of 1980, 1991, 2000, 2010 and the inter-census estimates, obtained from IBGE.

\section{Statistical analysis}

Crude mortality rates (CRs) were calculated to assess the annual risk of NTDs deaths in the state population. To compare studies in different locations and populations globally and nationally, we tried to reduce the effect of age differences between populations by calculating age-standardized mortality rates (ASRs). For the standardization, we used the direct method, Brazilian population of 2010 census as standard. The rates were calculated dividing the number of deaths by mid-period yearly population, expressed per 100000 inhabitants. For the analysis of the age-specific rates, data were grouped into the following age groups: 0 to 19, 20 to 39, 40 to 59 , and 60 plus years of age. We also calculated proportional mortality ratios (PMRs), dividing the number of NTD 


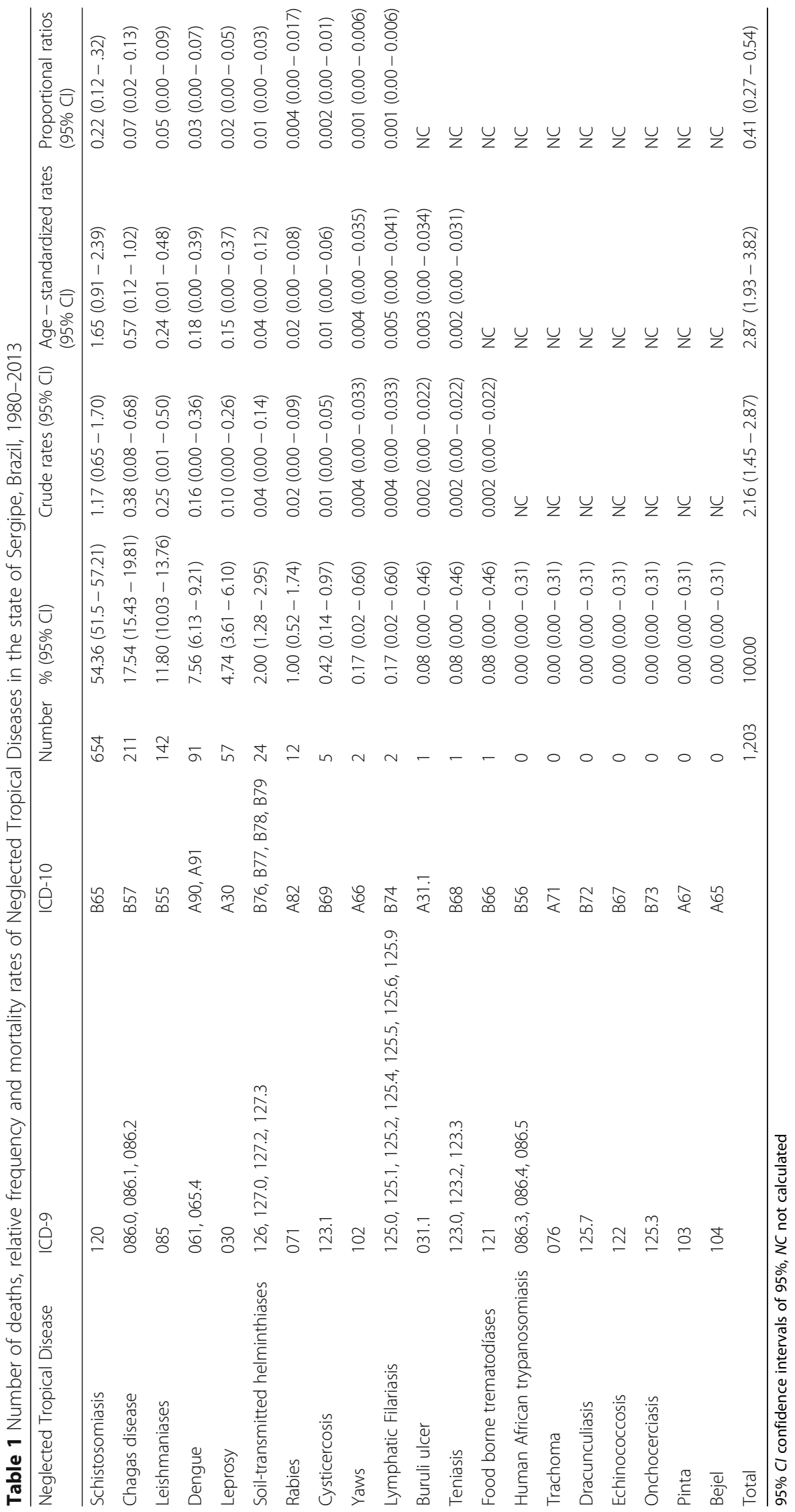


deaths by the total number of deaths, following multiplying by 100 .

Trend analyses were performed using the Joinpoint Regression Program version 4.2.0.2 [9], based on the calculation of the annual percent change (APC) and its respective $95 \%$ confidence intervals $(95 \% C I)$. Through the segmented log-linear regression, the Joinpoint method enables the description of a trend and the identification of recent changes, modeling linear segments united by inflexion points [10]. The option of heteroscedastic error used to model the trends was the Poisson model. The statistical significance was obtained using the permutation test of Monte Carlo, which through 9 999 permutations, chose the model with the best number of significant Joinpoints. We have also calculated the average annual percent change (AAPC) for the entire period and for the last 15 years [11]. If the APC or AAPC is positive and significant, there is an increasing trend; on the other hand, if the APC or AAPC is negative and significant, the trend is decreasing. If there is no significance, the trend it is considered stable.

\section{Results}

During the study period, we observed 306872 deaths in the state; the NTDs were mentioned as the underlying cause in 1203 certificates (0.39\%). Average number of deaths was 35.38 per year; average annual mortality rates (CRs, ASRs) were, respectively: 2.16 per 100000 (95\% CI: 1.45-2.87) and 2.87 per 100000 (95\% CI: 1.93-3.82); the PMR was $0.41 \%$ (95\% CI: $0.27-0.54$ ). Table 1 shows the main NTDs responsible for mortality, which were: Schistosomiasis, 654 deaths (54.36\%), followed by Chagas disease, 211(17.54\%) and Leishmaniases, 142 (11.80\%). The other diseases totalized 196 deaths (16.30\%).

Mortality time trends for NTDs (ASRs and PMRs), by Joinpoint regression analysis, are showed in Figs. 1 and 2, respectively. We observed increasing temporal trends for NTDs $\left(\right.$ AAPC $^{15}$ : 4.78; 95\% CI: 1.5-8.1), Schistosomiasis $\left(\right.$ AAPC $^{15}: 4.65 ; 95 \%$ CI: 0.8-8.7) and Chagas disease $\left(\mathrm{AAPC}^{15}: 7.13\right.$; 95\% CI: 5.4-8.9) in the last 15 years, according to the age-standardized rates, and stability of the mortality trends for Leishmaniases $\left(\mathrm{AAPC}^{15}\right.$ : 1.34; 95\% CI: -1.3-4.1). Proportional mortality ratios presented significant increases for NTDs $\left(\mathrm{AAPC}^{15}: 5.72\right.$; 95\% CI: 1.6-10.0) and Chagas disease $\left(\mathrm{AAPC}^{15}: 8.59\right.$; 95\% CI: 6.8-10.4); and stability for Schistosomiasis $\left(\mathrm{AAPC}^{15}\right.$ : 4.98; 95\% CI: -0.3-10.6) and Leishmaniases $\left(\mathrm{AAPC}^{15}: 0.78 ; 95 \% \mathrm{CI}:-1.5-3.1\right)$ in the last 15 years.

Table 2 summarizes the prevailing epidemiological characteristics of mortality from NTDs, highlighting gender, males (59.98\%) and age group, 60 plus (41.36\%). Similar results were observed for Schistosomiasis and Chagas disease. For Leishmaniases, age group 0-19 was the most predominant. Crude mortality rates, agespecific rates and proportional ratios have its trends exhibited in Table 3. Increasing trends were observed in the following age groups: $0-19$ (AAPC $^{15}: 3.31 ; 95 \%$ CI: $0.3-6.4$ ) and 60 plus (AAPC ${ }^{15}: 6.46$; 95\% CI: 3.6-9.4). A decreasing trend was observed in age group 20-39 $\left(\mathrm{AAPC}^{15}\right.$ : -2.40; 95\% CI: -4.2;-0.6). The findings in PMRs trends were similar, considering age-specific groups.

\section{Discussion}

The results from the present study have shown that NTDs are a real and worrisome problem in the state of Sergipe. Until the early 90s, the mortality rates were decreasing, but, from this period on, they showed an increasing trend, mainly for the NTDs (joint analysis), Schistosomiasis and Chagas disease. Unlike a recently published study, which showed Chagas disease as the NTD responsible for the highest mortality in Brazil, followed by Schistosomiasis and Leishmaniases [12], especially in Sergipe, there in an

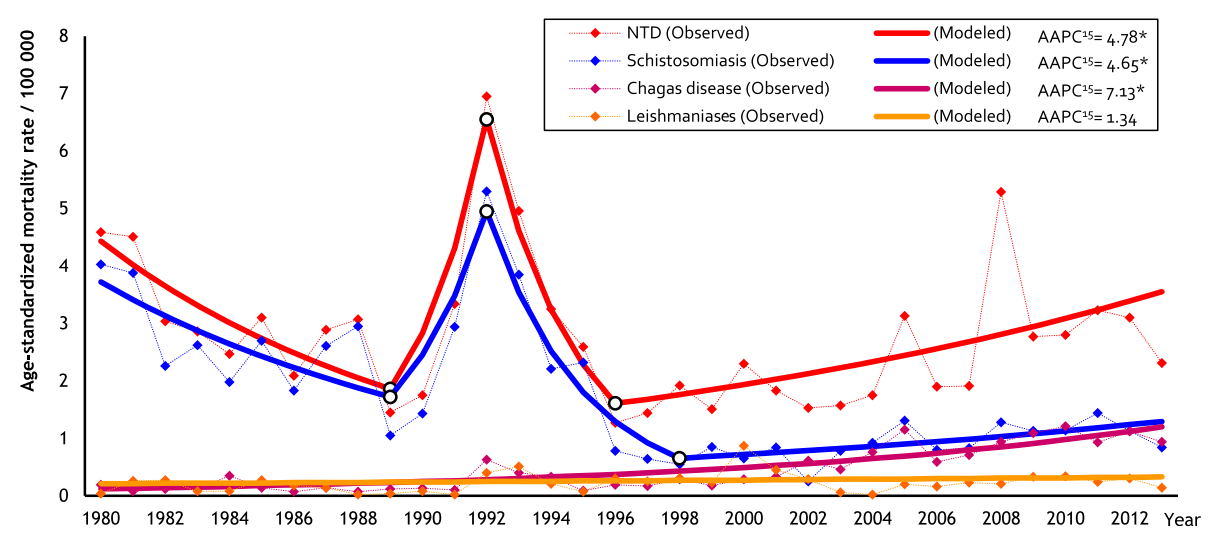

Fig. 1 Trends of age-standardized mortality rates by NTDs in the state of Sergipe, Brazil, 1980-2013. * Statistically important. AAPC ${ }^{15}$ : Annual percentage change in the last 15 years 


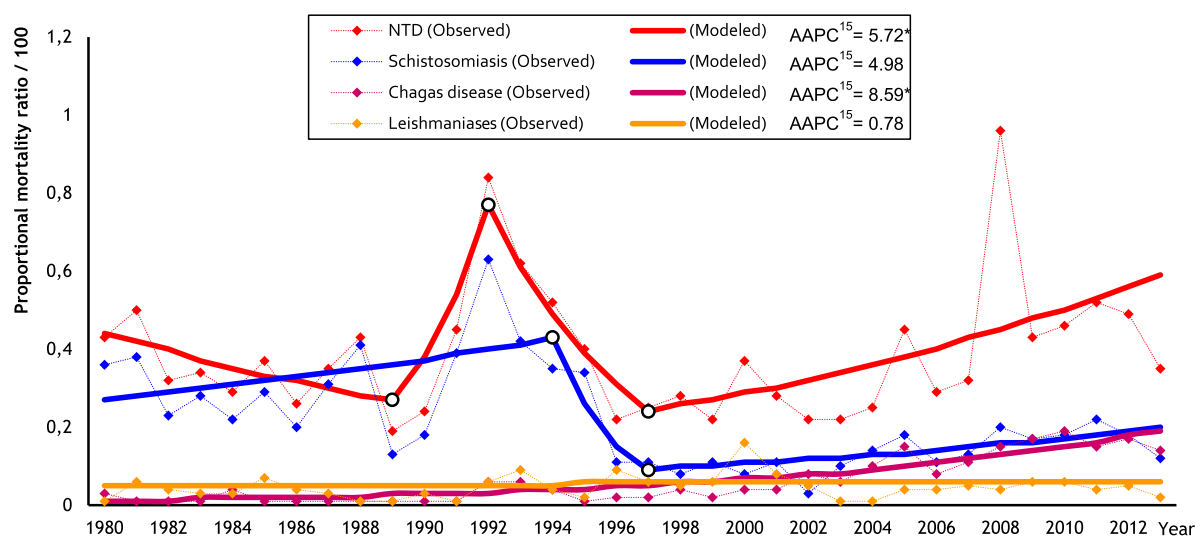

Fig. 2 Trends of proportional mortality ratios by NTDs in the state of Sergipe, Brazil, 1980-2013. * Statistically important. AAPC ${ }^{15}$ : Annual percentage change in the last 15 years

inversion, and Schistosomiasis appears with the highest mortality, followed by Chagas disease and Leishmaniases.

In Latin America, Brazil and particularly the Northeast Region showed the greatest endemic areas for Schistosomiasis, despite the control measures, mainly based on periodical researches in feces of individuals in endemic areas, followed by treatment of the positive cases $[12,13]$. These measures decreased the morbidity and mortality, but the disease was not eliminated, and continued to show significant mortality, such as the ones presented in our study $[14,15]$. The factors that renders more difficulty in controlling the disease are population migration, unsafe sanitary conditions and appearance of new foci $[12,15]$. This is not different in Sergipe, where variables such as temperature, low pluviometric indices, land use, land cover, and soil humidity are factors that contribute to the proliferation of Schistosomiasis and other neglected diseases. Schistosomiasis showed the highest mortality rates, similar to the State of Pernambuco, Northeast of Brazil [16], which predominates in most advanced ages, explained by the chronic nature of the disease and by its association with comorbidities, leading to more severe forms [14]. The lowest rates in younger age groups reflect the direction of the control and treatment programs for children and adolescents [17]. Despite the prevention and treatment programs, Schistosomiasis showed an increasing mortality trend in recent years. This is rather disturbing and reveals the need to prioritize surveillance measures related to the disease and investigation of the factors that are supporting the mortality, taking into account that Sergipe remains as an endemic area [18].

In Chagas disease, the number of deaths appeared higher in individuals over 40 years of age, which shows that infections probably acquired in the past turns prominent in in this age group [19], since acute infections do not play a significant role to mortality in Brazil. Due to the chronic nature of this entity and the increase in life expectancy of the population, it will probably remain high in the future [20]. There are important

Table 2 Epidemiological characteristics of mortality from Neglected Tropical Diseases in the state of Sergipe, Brazil, 1980-2013

\begin{tabular}{|c|c|c|c|c|c|c|c|c|c|c|c|c|}
\hline & \multicolumn{3}{|c|}{ Neglected Tropical Diseases } & \multicolumn{3}{|c|}{ Schistosomiasis } & \multicolumn{3}{|c|}{ Chagas disease } & \multicolumn{3}{|c|}{ Leishmaniases } \\
\hline & $\mathrm{N}$ & $\%$ & $95 \% \mathrm{Cl}$ & $\mathrm{N}$ & $\%$ & $95 \% \mathrm{Cl}$ & $\mathrm{N}$ & $\%$ & $95 \% \mathrm{Cl}$ & $\mathrm{N}$ & $\%$ & $95 \% \mathrm{Cl}$ \\
\hline \multicolumn{13}{|l|}{ Gender $^{a}$} \\
\hline Male & 721 & 59.98 & $57.15-62.77$ & 388 & 59.42 & $55.54-63.21$ & 141 & 66.82 & $60.03-73.14$ & 89 & 62.68 & $54.17-70.64$ \\
\hline Female & 481 & 40.02 & $37.23-42.85$ & 265 & 40.58 & $36.79-44.46$ & 70 & 33.18 & $26.86-39.97$ & 53 & 37.32 & $29.36-45.83$ \\
\hline \multicolumn{13}{|l|}{$\mathrm{Age}^{\mathrm{a}}$} \\
\hline $0-19$ & 156 & 13.47 & $11.56-15.57$ & 18 & 2.92 & $1.74-4.58$ & 1 & 0.48 & $0.01-2.63$ & 69 & 50.36 & $41.7-59.01$ \\
\hline $20-39$ & 168 & 14.51 & $12.53-16.67$ & 71 & 11.53 & $9.11-14.32$ & 23 & 10.95 & $7.07-15.98$ & 36 & 26.27 & $19.13-34.48$ \\
\hline $40-59$ & 355 & 30.66 & $28.01-33.4$ & 219 & 35.55 & $31.77-39.48$ & 82 & 39.05 & $32.41-46.0$ & 21 & 15.33 & $9.75-22.47$ \\
\hline $60+$ & 479 & 41.36 & $38.51-44.26$ & 308 & 50 & $45.98-54.02$ & 104 & 49.52 & $42.57-56.49$ & 11 & 8.03 & $4.08-13.91$ \\
\hline Total & 1203 & 100.00 & & 654 & 100.00 & & 211 & 100.00 & & 142 & 100.00 & \\
\hline
\end{tabular}


Table 3 Joinpoint regression analysis of mortality rates for Neglected Tropical Diseases by age group in the state of Sergipe, Brazil, 1980-2013

\begin{tabular}{|c|c|c|c|c|c|c|c|c|c|c|}
\hline \multirow[t]{2}{*}{ Age group } & \multicolumn{2}{|c|}{ Rates per 100000} & \multirow[t]{2}{*}{ Joinpoints } & \multicolumn{3}{|l|}{ Trends } & \multicolumn{2}{|c|}{ Entire period } & \multicolumn{2}{|c|}{ Last 15 years } \\
\hline & Start & Final & & Period & APC & $95 \% \mathrm{Cl}$ & AAPC & $95 \% \mathrm{Cl}$ & $\mathrm{AAPC}^{15}$ & $95 \% \mathrm{Cl}$ \\
\hline \multicolumn{11}{|c|}{ Crude mortality and age-specific rates } \\
\hline $0-19$ & 0.31 & 0.25 & 0 & $1980-2013$ & $3.31^{\mathrm{a}}$ & $0.3 ; 6.4$ & $3.31^{\mathrm{a}}$ & $0.3 ; 6.4$ & $3.31^{\mathrm{a}}$ & $0.3 ; 6.4$ \\
\hline $20-39$ & 1.77 & 0.66 & 0 & $1980-2013$ & $-2.40^{\mathrm{a}}$ & $-4.2 ;-0.6$ & $-2.40^{\mathrm{a}}$ & $-4.2 ;-0.6$ & $-2.40^{\mathrm{a}}$ & $-4.2 ;-0.6$ \\
\hline \multirow[t]{3}{*}{$40-59$} & 10.60 & 3.11 & 2 & $1980-1993$ & 2.84 & $-4.0 ; 10.1$ & -0.6 & $-12.5 ; 12.9$ & 3.45 & $-2.2 ; 9.4$ \\
\hline & & & & $1993-1996$ & -31.56 & $-83.1 ; 177.6$ & & & & \\
\hline & & & & $1996-2013$ & 3.45 & $-2.2 ; 9.4$ & & & & \\
\hline \multirow[t]{4}{*}{$60+$} & 12.93 & 11.63 & 3 & $1980-1989$ & $-8.32^{\mathrm{a}}$ & $-15.7 ;-0.2$ & 0.4 & $-8.6 ; 10.3$ & $6.46^{\mathrm{a}}$ & $3.6 ; 9.4$ \\
\hline & & & & $1989-1992$ & 62.46 & $-33.8 ; 298.8$ & & & & \\
\hline & & & & $1992-1996$ & -32.90 & $-55.2 ; 0.5$ & & & & \\
\hline & & & & $1996-2013$ & $6.46^{\mathrm{a}}$ & $3.6 ; 9.4$ & & & & \\
\hline \multirow[t]{4}{*}{ All (CR) } & 2.81 & 1.96 & 3 & $1980-1989$ & -8.80 & $-17.5 ; 0.8$ & 0.1 & $-11.4 ; 13.1$ & $5.64^{\mathrm{a}}$ & $1.6 ; 9.8$ \\
\hline & & & & $1989-1992$ & 52.58 & $-56.2 ; 432.0$ & & & & \\
\hline & & & & $1992-1997$ & -22.61 & $-44.3 ; 7.6$ & & & & \\
\hline & & & & $1997-2013$ & $5.64^{\mathrm{a}}$ & $1.6 ; 9.8$ & & & & \\
\hline \multirow[t]{4}{*}{ Schistosomiasis (CR) } & 2.37 & 0.68 & 3 & $1980-1989$ & $-7.44^{\mathrm{a}}$ & $-13.1 ;-1.4$ & -2.3 & $-9.9 ; 5.9$ & $5.28^{\mathrm{a}}$ & $1.0 ; 9.7$ \\
\hline & & & & $1989-1992$ & 47.21 & $-35.0 ; 233.2$ & & & & \\
\hline & & & & $1992-1998$ & $-28.49^{\mathrm{a}}$ & $-40.8 ;-13.7$ & & & & \\
\hline & & & & $1998-2013$ & $5.28^{\mathrm{a}}$ & $1.0 ; 9.7$ & & & & \\
\hline \multirow[t]{5}{*}{ Chagas Disease (CR) } & 0.18 & 0.77 & 4 & $1980-1989$ & -12.70 & $-28.6 ; 6.7$ & 4.7 & $-15.7 ; 30.0$ & $9.7^{\mathrm{a}}$ & $3.1 ; 16.7$ \\
\hline & & & & $1989-1992$ & 95.18 & $-77.8 ; 1613.6$ & & & & \\
\hline & & & & $1992-1995$ & -31.44 & $-77.7 ; 110.5$ & & & & \\
\hline & & & & $1995-2010$ & $14.99^{\mathrm{a}}$ & $10.2 ; 20.0$ & & & & \\
\hline & & & & $2010-2013$ & -7.68 & $-29.1 ; 20.2$ & & & & \\
\hline Leishmaniases (CR) & 0.09 & 0.14 & 0 & $1980-2013$ & -0.11 & $-2.4 ; 2.2$ & -0.11 & $-2.4 ; 2.2$ & -0.11 & $-2.4 ; 2.2$ \\
\hline \multicolumn{11}{|c|}{ Proportional mortality ratios } \\
\hline $0-19$ & 0.08 & 0.20 & 0 & $1980-2013$ & $7.04^{\mathrm{a}}$ & $3.5 ; 10.7$ & $7.04^{\mathrm{a}}$ & $3.5 ; 10.7$ & $7.04^{\mathrm{a}}$ & $3.5 ; 10.7$ \\
\hline $20-39$ & 0.73 & 0.30 & 0 & $1980-2013$ & $-2.53^{\mathrm{a}}$ & $-4.2 ;-0.8$ & $-2.53^{\mathrm{a}}$ & $-4.2 ;-0.8$ & $-2.53^{\mathrm{a}}$ & $-4.2 ;-0.8$ \\
\hline \multirow[t]{3}{*}{$40-59$} & 1.43 & 0.56 & 2 & $1980-1993$ & 2.95 & $-2.6 ; 8.8$ & 0.0 & $-10.7 ; 12.0$ & 5.11 & $-0.8 ; 11.4$ \\
\hline & & & & $1993-1996$ & -33.30 & $-80.7 ; 130.8$ & & & & \\
\hline & & & & $1996-2013$ & 5.11 & $-0.8 ; 11.4$ & & & & \\
\hline \multirow[t]{4}{*}{$60+$} & 0.32 & 0.31 & 3 & $1980-1989$ & $-7.34^{\mathrm{a}}$ & $-13.9 ;-0.3$ & 1.0 & $-7.5 ; 10.3$ & $6.79^{\mathrm{a}}$ & $3.7 ; 10.0$ \\
\hline & & & & $1989-1992$ & 58.97 & $-30.8 ; 265.3$ & & & & \\
\hline & & & & $1992-1996$ & -31.29 & $-53.8 ; 2.1$ & & & & \\
\hline & & & & $1996-2013$ & $6.79^{\mathrm{a}}$ & $3.7 ; 10.0$ & & & & \\
\hline \multirow[t]{4}{*}{ All } & 0.43 & 0.35 & 3 & $1980-1989$ & -5.47 & $-13.3 ; 3.1$ & 0.9 & $-9.5 ; 12.4$ & $5.72^{\mathrm{a}}$ & $1.6 ; 10.0$ \\
\hline & & & & $1989-1992$ & 42.32 & $-52.3 ; 324.8$ & & & & \\
\hline & & & & $1992-1997$ & -20.51 & $-41.9 ; 8.8$ & & & & \\
\hline & & & & $1997-2013$ & $5.72^{\mathrm{a}}$ & $1.6 ; 10.0$ & & & & \\
\hline \multirow[t]{3}{*}{ Schistosomiasis } & 0.36 & 0.12 & 2 & $1980-1994$ & 3.29 & $-0.3 ; 7.1$ & -0.9 & $-10.6 ; 9.7$ & 4.98 & $-0.3 ; 10.6$ \\
\hline & & & & $1994-1997$ & -40.21 & $-80.8 ; 86.4$ & & & & \\
\hline & & & & $1997-2013$ & 4.98 & $-0.3 ; 10.6$ & & & & \\
\hline Chagas Disease & 0.03 & 0.14 & 0 & $1980-2013$ & $8.59^{\mathrm{a}}$ & $6.8 ; 10.4$ & $8.59^{\mathrm{a}}$ & $6.8 ; 10.4$ & $8.59^{\mathrm{a}}$ & $6.8 ; 10.4$ \\
\hline Leishmaniases & 0.01 & 0.02 & 0 & $1980-2013$ & 0.78 & $-1.5 ; 3.1$ & 0.78 & $-1.5 ; 3.1$ & 0.78 & $-1.5 ; 3.1$ \\
\hline
\end{tabular}


regional differences related to mortality that can be explained by the efficacy of control measures and vector eradication programs [21]. The latter is paramount in Sergipe, since disease vector has not been eradicated. The mortality trends in Sergipe are increasing and, similar to the mortality for Chagas disease in most areas of the Northeast and North of Brazil, it will remain as an important health problem in coming years $[22,23]$. That will pose a great challenge for policy makers, to ensure greater coverage of control measures in the population. Thus, public health preventive actions are needed, followed by appropriate monitoring and evaluation. In spite of the efforts to reduce transmission, there is actually no impact in decreasing mortality rates $[24,25]$.

Visceral Leishmaniasis is the most common type in the Northeast Region and in Sergipe as well. There was a greater number of deaths in the age group $0-19$, and subsequent reduction in the age group 60 plus, which may reflect a sub-notification in the number of deaths of elderly patients. Younger individuals are more prone to have their diagnosis established, rendering a great number of notifications in this age group [26]. The higher mortality rates in children may reflect greater contact with vectors and hosts, immature immunity, and nutritional deficiencies $[27,28]$. Studies conclude that the high lethality produced by Leishmaniasis is due to, in addition to other factors, the lack of study on the efficacy of the drugs available in the market [29]. In Sergipe, the mortality trend is stable, despite the disease, vector and host control programs, which favors the need to prioritize measures of surveillance of disease transmission, and treatment.

Mortality rates for the NTDs were higher in elderly patients, who faces the chronic nature of the diseases and comorbidities, thus, contributing to worse outcomes. Besides, there has been some difficulties in the implementation public health policies in the state, and the mere existence of health units does not guarantee full and proper observation of the population demands [8].

The present study was conducted using secondary data, and it may show limitations by sub-notifications and diagnostic errors. Deaths due to NTDs' complications might not be registered correctly, especially if we consider that only the underlying cause of death was verified. Other causes of death, even citing NTDs in other lines were not included, which eventually underestimates the mortality rates. Other authors also faced limitations in research using secondary data $[12,20]$.

\section{Conclusions}

In conclusion, NTDs continue to be important mortality causes in the state of Sergipe, showing increasing mortality trends in the last 15 years. It is necessary to revise public health policies for the control of these neglected diseases, especially to decrease those high mortality rates.

\section{Additional file}

Additional file 1: Multilingual abstracts in the five official working languages of the United Nations. (PDF $555 \mathrm{~kb}$ )

\section{Abbreviations \\ ASRs: Age-standardized rates; CRs: Crude rates; HAT: Human African Trypanosomiasis; HDls: Human Development Indices; IBGE: Instituto Brasileiro de Geografia e Estatística [Brazilian Institute of Geography and Statistics]; NTDs: Neglected tropical diseases; PMRs: Proportional mortality ratios; SIM: Sistema de Informações sobre Mortalidade [Mortality Information System]; WHO: World Health Organization}

\section{Acknowledgements}

Not applicable.

Availability of data and materials

Not applicable.

\section{Authors' contributions}

All authors have contributed to the conception and design of the study. MACA, DMD and LTV had access to the database and conducted the data analysis. CAL and AMS conducted additional analysis and interpretations. MACA and DMD have written the manuscript. MACA, LTV, CAL and AMS conducted the critical review of the manuscript. All authors have read and approved the final manuscript.

\section{Competing interests}

The authors declare that they have no competing interests.

\section{Consent for publication}

Not applicable.

\section{Ethics approval and consent to participate}

The study was approved by the Human Research Ethics Committee of the Federal University of Sergipe, Brazil, under the registration number 33283714.8.0000.5546 on 08 Nov 2014.

Received: 26 January 2016 Accepted: 23 December 2016

Published online: 08 February 2017

\section{References}

1. Hotez PJ, Aksoy S. An interfaith dialogue on the neglected tropical diseases. PLoS Negl Trop Dis. 2011;5:e1240.

2. WHO: World Health Organization. http://www.who.int/neglected_diseases/ about/en/. Accessed 29 Sept 2015.

3. Werneck GL, Hasselmann MH, Gouvêa TG. An overview of studies on nutrition and neglected diseases in Brazil. Cien Saude Colet. 2011;16:39-62.

4. Lindoso JA, Lindoso AA. Neglected tropical diseases in Brazil. Rev Inst Med Trop Sao Paulo. 2009;51:247-53.

5. Hotez PJ. The giant anteater in the room: Brazil's neglected tropical diseases problem. PLoS Negl Trop Dis. 2008;2:e177.

6. IBGE (Instituto Brasileiro de Geografia e Estatística). Síntese do Estado de Sergipe em 2015. http://www.ibge.gov.br/estadosat/perfil.php?sigla=se. Accessed 29 Feb 2016.

7. IBGE (Instituto Brasileiro de Geografia e Estatística). Contagem da População 2014. http://cidades.ibge.gov.br/xtras/perfil.php?lang=\&codmun= 280030\&search=sergipe|aracaju|infograficos:-informacoes-completas Accessed 29 Feb 2016

8. Final, produto VI-versão. Avaliação ambiental estratégica do PRODETUR nacional no Estado de Sergipe, 2014. http://www.turismo.gov.br/sites/ default/turismo/DPROD/AVALIACAO_AMBIENTAL/SE/AAE_SE.pdf. Accessed 29 Feb 2016.

9. Statistical Methodology and Applications Branch, Surveillance Research Program, National Cancer Institute: Joinpoint Regression Program, Version 4. 2.0.2 - June 2015. http://surveillance.cancer.gov/joinpoint/.

10. Kim HJ, Fay MP, Feuer EJ, Midthune DN. Permutation tests for joinpoint regression with applications to cancer rates. Stat Med. 2000;19:335-51.

11. Clegg LX, Hankey BF, Tiwari R, Feuer EJ, Edwards BK. Estimating average annual per cent change in trend analysis. Stat Med. 2009;28:3670-82. 
12. Martins-Melo FR, Ramos AN, Alencar CH, Heukelbach J. Mortality from neglected tropical diseases in Brazil, 2000-2011. Bull World Health Organ. 2016;94:103-10.

13. Hotez PJ, Fujiwara RT. Brazil's neglected tropical diseases: an overview and a report card. Microbes Infect. 2014;16:601-6.

14. Martins-Melo FR, Pinheiro MC, Ramos AN, Alencar CH, Bezerra FS,

Heukelbach J. Trends in schistosomiasis-related mortality in Brazil, 2000-2011. Int J Parasitol. 2014;44:1055-62.

15. Amaral RS, Tauil PL, Lima DD, Engels D. An analysis of the impact of the Schistosomiasis Control Programme in Brazil. Mem Inst Oswaldo Cruz. 2006; 101 Suppl 1:79-85

16. Resendes AP, Souza-Santos R, Barbosa CS. Hospitalization and mortality from mansoni schistosomiasis in the state of Pernambuco, Brazil, 1992/2000. Cad Saude Publica. 2005;21:1392-401.

17. Silveira AC, Vasconcelos MF, Melo JE. Mortality caused by schistosomiasis in Brazil, 1977-1986. Rev Soc Bras Med Trop. 1990;23:133-40.

18. DATASUS. http://tabnet.datasus.gov.br/cgi/deftohtm.exe?sinan/pce/cnv/ pce.def. Accessed 29 Sept 2015

19. Alves RM, Thomaz RP, Almeida EA, Wanderley JS, Guariento ME. Chagas' disease and ageing: the coexistence of other chronic diseases with Chagas' disease in elderly patients. Rev Soc Bras Med Trop. 2009;42:622-8.

20. Martins-Melo FR, Alencar CH, Ramos AN, Heukelbach J. Epidemiology of mortality related to Chagas' disease in Brazil, 1999-2007. PLoS Negl Trop Dis. 2012;6:e1508.

21. Dias JC, Prata A, Correia D. Problems and perspectives for Chagas disease control: in search of a realistic analysis. Rev Soc Bras Med Trop. 2008:41:193-6.

22. Drumond JA, Marcopito LF. Internal migration and distribution of Chagas disease mortality, Brazil, 1981-1998. Cad Saude Publica. 2006;22:2131-40.

23. Silveira AC. Entomological survey (1975-1983). Rev Soc Bras Med Trop. 2011; 44 Suppl 2:26-32.

24. Ostermayer AL, Passos AD, Silveira AC, Ferreira AW, Macedo V, Prata AR. The national survey of seroprevalence for evaluation of the control of Chagas disease in Brazil (2001-2008). Rev Soc Bras Med Trop. 2011;44 Suppl 2:108-21.

25. Martins-Melo FR, Ramos AN, Alencar CH, Heukelbach J. Prevalence of Chagas disease in Brazil: a systematic review and meta-analysis. Acta Trop. 2014;130:167-74

26. Martins-Melo FR, Lima MS, Ramos AN, Alencar CH, Heukelbach J. Mortality and case fatality due to visceral leishmaniasis in Brazil: a nationwide analysis of epidemiology, trends and spatial patterns. PLoS One. 2014;9:e93770.

27. Oliveira AL, Paniago AM, Dorval ME, Oshiro ET, Leal CR, Sanches M, Cunha RV, Bóia MN. Emergent outbreak of visceral leishmaniasis in Mato Grosso do Sul State. Rev Soc Bras Med Trop. 2006;39:446-50.

28. Madalosso G, Fortaleza CM, Ribeiro AF, Cruz LL, Nogueira PA, Lindoso JA. American visceral leishmaniasis: factors associated with lethality in the state of São Paulo, Brazil. J Trop Med. 2012;2012:281572.

29. Alvarenga DG, Escalda PM, Costa AS, Monreal MT. Visceral leishmaniasis: retrospective study on factors associated with lethality. Rev Soc Bras Med Trop. 2010;43:194-7.

\section{Submit your next manuscript to BioMed Central and we will help you at every step:}

- We accept pre-submission inquiries

- Our selector tool helps you to find the most relevant journal

- We provide round the clock customer support

- Convenient online submission

- Thorough peer review

- Inclusion in PubMed and all major indexing services

- Maximum visibility for your research

Submit your manuscript at www.biomedcentral.com/submit
Biomed Central 